\title{
THE RELAPSE IN SCARLET FEVER
}

BY

\author{
JAMES S. ANDERSON, M.A., M.D., D.P.H., \\ Medical Superintendent, Leeds City Hospitals, and \\ Lecturer in Infectious Diseases, University of Leeds.
}

In this country during the past decade the prevalence of a benign type of scarlet fever has been reflected in the case mortality which has seldom exceeded one per cent. in any of the great cities. The present day chances of a severe attack of the disease may be illustrated by the statement that of 1,743 admissions to the Leeds City Hospital in 1933, only one manifested the malignant type, while twenty-three were examples of the septic type. In many parts of the country, isolation of a large proportion of cases of scarlet fever is still the normal practice. It is not intended within the scope of this paper to criticize this policy, but it is proposed to draw attention to a problem which may arise when an epidemic of benign scarlet fever is prevalent and isolation accommodation is consequently strained. The problem is that of the relapse.

The development of immunity to the disease is the normal expectation after an attack of scarlet fever. That this is not invariable is shown by the occurrence of second attacks and relapses. Second attacks, developing some months or years after the first attack, are according to Rolleston ${ }^{1}$ more uncommon than relapses, yet it is noteworthy that, of the admissions to the Leeds City Hospital in 1933, 3.5 per cent. gave a history of a previous attack. As regards relapses the same authority, after making allowance for errors in the original diagnosis, estimates that a return of all the characteristic symptoms of the disease occurs in about one per cent. of all cases. The relapse rates for the Leeds City Hospital for the years 1931, 1932 and 1933, were $3 \cdot 6,4 \cdot 0$, and $4 \cdot 3$ per cent. respectively. Such rates appear to be high and they give rise to an administrative problem, as they indicate an additional burden on the available accommodation of the hospital and a definite increase in the cost of treatment of scarlet fever.

TABLE 1.

Time of OCCURREnce OF ReLAPSES.

\begin{tabular}{|c|c|c|c|c|c|c|c|c|c|}
\hline \multirow{7}{*}{\multicolumn{2}{|c|}{$\begin{array}{l}\text { First week } \\
\text { Second ," } \\
\text { Third ", } \\
\text { Fourth ", } \\
\text { Later }\end{array}$}} & $\ldots$ & $\ldots$ & $\ldots$ & $\ldots$ & 1931. & $\begin{array}{c}1932 . \\
1\end{array}$ & $\begin{array}{c}1933 . \\
1\end{array}$ & $\begin{array}{c}\text { Total } \\
2\end{array}$ \\
\hline & & $\ldots$ & $\ldots$ & $\ldots$ & $\ldots$ & 12 & 7 & 4 & 23 \\
\hline & & $\ldots$ & $\ldots$ & $\ldots$ & $\ldots$ & 12 & 12 & 14 & 38 \\
\hline & & $\cdots$ & $\ldots$ & $\ldots$ & $\ldots$ & 11 & 10 & 25 & 46 \\
\hline & & $\cdots$ & $\cdots$ & $\cdots$ & $\cdots$ & 17 & 8 & 26 & 51 \\
\hline & & & & tal & $\cdots$ & $\overline{52}$ & $\overline{38}$ & $\overline{70}$ & 160 \\
\hline & & & & & & - & - & - & \\
\hline
\end{tabular}


The time of occurrence of the relapses is noted in table 1 . It will be observed that two relapses are recorded to have taken place in the first week and twenty-three in the second. The writer is aware that criticism may be directed to the original diagnosis of scarlet fever in these cases. It may be stated, however, that no case has been included in which there was not reasonable evidence in support of the original diagnosis at the time of admission of the patient.

It is generally accepted that the Dick test furnishes an indication of susceptibility or immunity to scarlet fever. In the first three days of the disease, over 70 per cent. of patients give a positive reaction. This is probably an under-statement, as Zingher ${ }^{2}$ reports 93 and 100 per cent. in different series, and $\mathrm{Joe}^{3}$ reports 95 per cent. The latter, however, states that he was using a toxin selected from others on account of its sensitiveness. As a result of the gradual development of immunity owing to the stimulus of the disease, the reaction tends to become negative by the end of the third week in the majority of patients. In the work of Zingher, to which reference has already been made, a reversal of the positive Dick reaction in the early stage to a negative in convalescence was noted in the whole of the 93 per cent., while in Joe's work, the 95 per cent. was reduced to about 5 per cent. after the thirtieth day. In contrast to these ideal results, it should be noted that in a later series of patients James, Joe and Swyer ${ }^{4}$ gave a percentage of 57 in whom the reaction was still positive on the twenty-eighth day and after. The difficulties in the standardization of scarlet fever toxin appear to be responsible for these discrepant results.

An examination of the records of Dick tests in scarlet fever patients in the Leeds City Hospital in 1933 shows that positive reactions persisting to the end of the third week have been frequent. The conclusion appears to be unavoidable that the present benign type of scarlet fever provides in many cases insufficient stimulus for the development of immunity. Table 2 gives the details of Dick tests in 1,592 patients. As far as circumstances permitted, tests were performed on admission and again on approximately the twenty-

TABLE 2.

Dick test RESULtS in RELATION to RELAPSES.

1933.

Dick test positive on admission

Positive at end of third week ...

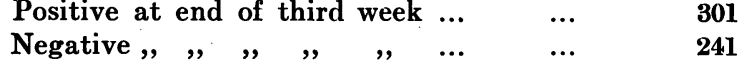

Not tested later $\quad \ldots \quad \ldots \quad \ldots \quad 238$

Dick test negative on admission ... $\quad \ldots \quad 435$

$\begin{array}{ccc}\begin{array}{c}\text { Number } \\ \text { of } \\ \text { patients. }\end{array} & \begin{array}{c}\text { Number } \\ \text { of } \\ \text { relapses. }\end{array} & \begin{array}{c}\text { Percentage } \\ \text { of } \\ \text { relapses. }\end{array}\end{array}$

Dick test recorded only in convalescence

Negative

No record

$\begin{array}{rrrrr}\cdots & \ldots & \ldots & \ldots & \mathbf{5 6} \\ \cdots & \ldots & \ldots & \ldots & \mathbf{3 2 1} \\ & & \text { Total } & \ldots & \mathbf{1 , 5 9 2}\end{array}$

27

8.9

$0 \cdot 8$

2
14 $\quad 5 \cdot 8$

Total $\cdots \quad \underline{1,592}$

\begin{tabular}{ll}
1 & $1 \cdot 7$ \\
22 & $6 \cdot 8$ \\
\hline 70 & - \\
- & $4 \cdot 3$ \\
\hline
\end{tabular}


first day of the disease. The large number of negative reactors on admission includes a considerable proportion of late admissions to hospital. The majority of the patients tested in convalescence only were also admitted late in the disease. The patients of whom records are not available include, among others, serum-treated cases and cases in whom the reading of the Dick test was recorded as doubtful owing to the brightness of the rash.

With regard to the incidence of relapses in patients treated with scarlatinal antitoxin, Rolleston ${ }^{1}$ records that he met no example in a series of over 350 cases selected for their severity. Burton and Balmain ${ }^{5}$, on the other hand, recorded eighteen relapses ( $4 \cdot 16$ per cent.) among 432 consecutive cases of scarlet fever treated with scarlatinal antitoxin. Their total may be presumed to include many mild cases in whom the stimulus of the primary attack may have been insufficient to produce immunity. In Leeds it has been the practice to reserve antitoxin for the more acute cases. During the period 1931 to 1933,208 patients received antitoxin. Intravenous administration was employed in 107 cases, the route in the remainder being intramuscular. Of the serum-treated cases, only four relapsed (1.9 per cent.), and these received the antitoxin intramuscularly. As might be expected, these relapses occurred rather late in the course of the disease and presumably after the antitoxin had been eliminated, the time of occurrence being the eighteenth, twenty-seventh, thirty-fourth and thirty-sixth days. It is of interest to note that while the relapse rate for 208 serum-treated cases was 1.9 per cent., the rate for 3,619 non-serum-treated cases was 5.6 per cent. As the average severity of the disease differed in the two groups, no inference can be drawn as to the effect of the antitoxin on the relapse rate, and it should be borne in mind that Burton and Balmain ${ }^{5}$ have recorded a relapse rate of 4.16 per cent. for consecutive antitoxin-treated cases.

The possibility of a high relapse rate in benign scarlet fever creates a problem which demands attention. It may be suggested that the solution lies in the reduction of the period of isolation. Banks ${ }^{6}$ advocates and practices the intravenous administration of antitoxin to all cases, and the discharge from hospital in a little over a fortnight. As most relapsing cases are probably reinfected while under treatment in hospital, this procedure would undoubtedly cut down the relapse rate, but the policy of administering antitoxin by the intravenous route to admittedly benign cases has not met with general approval. Few local authorities which attempt the hospitalization of scarlet fever on a large scale have cut down the period of isolation to less than four weeks, and in hospitals there is a tendency to accept the relapse with the same equanimity with which a ' return' case is accepted. The isolation of patients in whom the transition of the Dick test from positive to negative fails to take place may be suggesed and is, indeed, frequently carried out, but in epidemic times this becomes impossible owing to the lack of accommodation. The solution of the relapse problem advocated here assumes the inadequacy of the primary stimulus at the onset of the disease. The stimulus is increased therefore and maintained by the administration of 
prophylactic scarlatinal toxin. The procedure adopted in the Leeds City Hospital is as follows:-

All patients, to whom the administration of antitoxin is not indicated, are Dick tested on admission to hospital. To all positive reactors a course of graduated doses of prophylactic toxin is given, the course beginning as soon as the temperature has fallen to normal. Injections of 500, 2,000, 5,000 and 20,000 skin doses are given at four day intervals. Thus the course is completed before the end of the third week when the patient is allowed up, at which stage the risks of reinfection tend to increase. The injections are well tolerated and do not appear to have the slightest adverse effect upon the disease. The procedure was tried out for some months in a double ward to which children under five years of age were admitted. Table 3 gives the details.

\section{TABLE 3.}

THE EFFECT OF PROPHYLACTIC TOXIN ON THE OCCURRENCE OF RELAPSES.

\begin{tabular}{|c|c|c|c|c|c|c|c|c|}
\hline & & & \multicolumn{2}{|c|}{$\begin{array}{l}\text { Number } \\
\text { of } \\
\text { admissions. }\end{array}$} & \multicolumn{2}{|c|}{$\begin{array}{c}\text { Number } \\
\text { of } \\
\text { relapses. }\end{array}$} & \multicolumn{2}{|c|}{$\begin{array}{l}\text { Number of patients } \\
\text { receiving } \\
\text { toxin injections. }\end{array}$} \\
\hline & & & $\mathbf{A}$ & B & $\mathbf{A}$ & B & $\mathbf{A}$ & B \\
\hline \multicolumn{9}{|c|}{1933} \\
\hline July & $\ldots$ & $\ldots$ & 33 & 113 & 3 & - & & \\
\hline August & $\ldots$ & $\ldots$ & 48 & 108 & 1 & 4 & & \\
\hline September & $\ldots$ & $\ldots$ & 65 & 222 & 1 & 2 & & \\
\hline October & $\ldots$ & $\ldots$ & 56 & 306 & 12 & 8 & 10 & - \\
\hline November & $\ldots$ & $\ldots$ & 70 & 290 & 2 & 12 & 59 & - \\
\hline December & $\ldots$ & $\ldots$ & 59 & 254 & - & 7 & 36 & - \\
\hline \multicolumn{9}{|c|}{1934} \\
\hline January & $\ldots$ & $\ldots$ & 36 & 230 & - & 9 & 28 & 1 \\
\hline February & $\ldots$ & $\ldots$ & 33 & 118 & - & 5 & 16 & 5 \\
\hline March & $\ldots$ & $\ldots$ & 38 & 152 & $\mathbf{1}$ & 5 & 33 & 10 \\
\hline April & $\ldots$ & $\ldots$ & 47 & 160 & - & 5 & 40 & 8 \\
\hline
\end{tabular}

Note: A-Ward receiving children under 5 years of age.

B-Other wards.

It should be noted that the toxin injections were commenced on October 30, 1933, with new admissions only, so that the procedure could not affect the occurrence of relapses until November. Although the results appeared to justify the extension of the treatment to other wards, it was decided to continue the administration of toxin as a routine in the infants' ward only, and to employ it in selected cases in the other wards, so that the other wards might continue to act as a control. During a period of six months, it may be stated that only one relapse has occurred in the infants' ward. In this case, the Dick test was recorded as 'pseudo and negative' on admission, in consequence of which the child did not receive toxin injections. Further, it is of interest to note that of 246 patients shown in table 3 as receiving toxin injections, only one relapsed. This patient was in a ward for older children where few had received toxin injections, and the relapse occurred thirty-five days after the last injection. 


\section{Conclusions.}

1. The benign type of scarlet fever at present prevalent in this country frequently fails to produce immunity in the individual.

2. As a result second attacks and relapses may be more common.

3. The prevention of relapses is sound economy and is beneficial to the individual.

4. The administration of scarlatinal toxin is suggested as a logical procedure in the prevention of relapses.

\section{REFERENCES.}

1. Rolleston, J. D., Acute Infectious Diseases, London, 1929, second edition.

2. Zingher, A., J. Am. Med. Ass., Chicago, 1924, LXXXIII, 432.

3. Joe, A., Bull. Hyg., London, 1934, VII, 431.

4. James, G. R., Joe, A., \& Swyer, R., J. Hyg., London, 1929, XXIX, 347.

5. Burton, A. H. G., \& Balmain, A. R., Lancet, London, 1928, i, 1060.

6. Banks, H. S., J. Hyg., London, 1933, XXXIII, 282. 